\title{
A RESPOSTA DE THOMAS REID AO CETICISMO
}

\author{
Thomas Reid's Reply to Skepticism
}

Vinícius França Freitas *

Resumo: O objetivo do artigo é apresentar e discutir o modo como a filosofia do senso comum de Thomas Reid responde ao ceticismo sobre a fiabilidade epistêmica das faculdades da mente. A hipótese aqui apresentada estabelece que a resposta reidiana possui três argumentos. Em primeiro lugar, Reid mostra porque é impossível provar a fiabilidade das faculdades da mente e porque os filósofos podem começar suas investigações aceitando a verdade das crenças devidas a estas faculdades. Em segundo lugar, Reid mostra que é inconsistente escolher uma destas faculdades como única fonte de crenças verdadeiras. Isto é arbitrário. Aqueles autores que escolhem, por exemplo, a consciência como única fonte de conhecimento fiável, apenas reforçam a defesa de que todas as faculdades da mente são igualmente fiáveis. Em terceiro lugar, se as faculdades da mente operam apropriadamente, isto é, quando a mente não é afetada por uma desordem ou doença, não há boas razões para colocar em questão sua fiabilidade e, portanto, questionar a verdade das crenças devidas a elas.

Palavras-chave: Senso comum. Ceticismo. Crença. Thomas Reid.

Abstract: The paper presents and discusses how Thomas Reid's philosophy of common sense replies to the skepticism about the epistemic reliability of the faculties of mind. The hypothesis is that Reid responds to the skeptical challenges with three arguments. First, he shows why it is impossible to prove the

* Doutor em filosofia (2017) pela Universidade Federal de Minas Gerais e pela Université Paris I Panthéon-Sorbonne (cotutela). Professor efetivo de filosofia da rede pública de ensino do Estado de Minas Gerais. Artigo recebido em 22/11/2018 e aprovado para publicação em 20/08/2019. 
reliability of the faculties of mind and why philosophical investigations might start by accepting the truth of beliefs arising from these faculties. Secondly, Reid notes the inconsistency in arbitrarily choosing one of these faculties as the only source of true beliefs. Authors who, for example, choose consciousness as the only source of reliable knowledge, only reinforce the claim that all faculties of mind are equally reliable. Thirdly, if the faculties of the mind work properly, that is, if our mind is not affected by any disorder or disease, there is no good reason to call them into question and to doubt the truth of their beliefs.

Keywords: Common sense. Skepticism. Belief. Thomas Reid.

\section{Introdução **}

filosofia do senso comum de Thomas Reid (1710-1796) é motivada
sobretudo pelo intuito de combater o ceticismo que, em sua visão,
impregnou todo o pensamento dos séculos XVII e XVIII, da filosofia de René Descartes (1590-1650) ao pensamento autodeclaradamente cético de David Hume ${ }^{1}$ (1711-1776). Já na 'Dedicatória' de sua primeira grande obra, Uma investigação sobre a mente humana a partir dos princípios do senso comum (1764), Reid chama a atenção para o que, a seu ver, são as consequências nocivas de uma posição filosófica cética:

Estou persuadido de que o ceticismo absoluto não destrói apenas a fé de um cristão, mas também a ciência de um filósofo e a prudência de um homem de entendimento comum. Estou persuadido que o injusto 'vive pela fé' assim como o 'justo', que se todas as crenças pudessem ser deixadas de lado, piedade, patriotismo, amizade, afeição paternal e virtude privada pareceriam tão ridículos quanto os sentimentos quixotescos. A busca pelo prazer, a ambição e a avareza devem ser fundadas sobre a crença assim como aquelas que são honrosas e virtuosas².

\footnotetext{
** Agradeço aos pareceristas anônimos da Síntese: Revista de Filosofia pelas sugestões e críticas que contribuíram imensamente para o desenvolvimento dos argumentos que apresento neste artigo.

${ }^{1} \mathrm{O}$ Tratado da natureza humana (1739-40) apresenta, como Reid o entende, um sistema de ceticismo que não permite o estabelecimento de nenhum fundamento para as crenças compartilhadas pelos seres humanos. O sistema humiano seria o mais radical de todos no tocante ao seu ceticismo, visto que suas conclusões implicam a impossibilidade de se assumir, como verdadeiras, as crenças sobre a existência do mundo externo e a existência da mente humana. A leitura do Tratado de Hume e a posição cética resultante da investigação humiana determinou decisivamente a direção do pensamento de Reid. O terceiro capítulo da biografia de Reid escrita por Alexander Fraser em 1898 é dedicado quase que exclusivamente ao impacto que a filosofia humiana do Tratado teve sobre a vida intelectual do filósofo e o modo como ela teria motivado a reflexão filosófica de Reid (FRASER, A. C. Thomas Reid. New York: Charles Scribner's Sons, 1898, p. 30-42).

${ }^{2}$ REID, T. Inquiry into the Human Mind on the Principles of Common Sense. Edinburgh: Edinburgh University Press, 1997, p. 04.
} 
A filosofia passa pelo período de uma 'crise cética', quando o ceticismo contaminaria todos os âmbitos do saber ${ }^{3}$. Responder adequadamente ao ceticismo, portanto, é preservar a possibilidade do conhecimento, da moral e da religião.

Diante deste cenário intelectual proeminentemente cético dos séculos XVII e XVIII, um cenário no qual Reid identifica princípios e consequências céticas em todos os sistemas filosóficos, o filósofo propõe um apelo ao 'senso comum' como via segura para se fugir ao ceticismo. Este seria o fundamento sólido sobre o qual o conhecimento humano poderia ser construído e preservado do ataque cético. Senso comum e filosofia devem ser reconciliados:

Nesta disputa desigual entre Senso Comum e Filosofia, esta última sempre acabará em desonra e prejuízo, de modo que ela nunca prosperará a menos que esta rivalidade seja posta de lado, que estas usurpações sejam abandonadas e sua amizade cordial seja restaurada. Pois, em realidade, o Senso Comum não possui nada da Filosofia, nem precisa de seu auxílio. Por outro lado, no entanto, a Filosofia (se me é permitido mudar a metáfora) não possui outra raiz senão os princípios do Senso Comum. Ela cresce deles e daí extrai seu alimento. Separada de suas raízes, sua honra murcha, sua seiva seca, ela morre e apodrece ${ }^{4}$.

A raiz do conhecimento é o 'senso comum'. O senso comum não é senão o conjunto dos princípios originais da mente que sugerem ao ser humano suas noções, crenças e os determinam no tocante às suas inclinações. Mais: o senso comum é composto das crenças que são resultados das operações destes princípios originais ${ }^{5}$. As crenças da faculdade da consciência, da

\footnotetext{
${ }^{3}$ Laurent Jaffro apresenta uma breve consideração, mas muito esclarecedora, acerca da proeminência da posição cética no fim do século XVII e início do século XVIII: "para compreender mais seriamente a situação própria do pensamento britânico saindo do século XVII, é preciso determinar a representação que este pensamento faz daquilo que é dominante na filosofia e, mais geralmente, na vida intelectual. Esta representação é inicialmente a constatação de uma catástrofe: o ceticismo domina a cena intelectual e pode arruinar os princípios mais bem estabelecidos da moral, da religião, da sociedade, da ciência e da filosofia. Qual a obra que faz um balanço enciclopédico da filosofia moderna? É o 'Dicionário de Bayle'. Que representação ela oferece do saber mais elaborado? Aquele de um triunfo do ceticismo em todos os âmbitos, seja da crença religiosa, da percepção sensível ou da conduta da vida. Os intelectuais difundem concepções perniciosas segundo as quais a vida ordinária é uma existência sob o regime não apenas do preconceito, mas da ilusão" (JAFFRO, L. "Les Recours Philosophiques au Sens Commun dans les Lumières Britanniques". In: Le Sens Commun. Dijon: Editions Universitaires de Dijon, 2006, p. 20). Esta descrição do espírito do pensamento filosófico do tempo condiz muito bem com a confissão de Reid de seus anseios na 'Dedicatória' da Investigação. Ver também, acerca da influência do ceticismo sobre a filosofia do período, a obra Scepticism in the Eighteenth Century, editada por Sébastien Charles e Plínio Smith. Sugiro, em especial, a leitura do capítulo sobre Reid e o ceticismo, intitulado, 'Can We Know Whether Scepticism is Right or Wrong? Reid's Criticism and Hume's Answer', de autoria de Claire Etchegaray (2013, p. 139-154).

${ }^{4}$ REID, 1997, p. 19.

${ }^{5}$ Discuto minha interpretação da noção de 'senso comum' em outro trabalho (FREITAS, V. "A noção de senso comum em Thomas Reid". In: Discurso, 2019, no prelo).
} 
memória e da percepção, as crenças imediatas (não adquiridas por raciocínio) e irresistíveis (o assentimento a elas é inevitável) da natureza humana, são crenças do senso comum. Reid as denomina 'princípios primeiros do senso comum'.

O objetivo deste artigo diz respeito justamente ao modo como a filosofia de Reid responde ao ceticismo sobre a fiabilidade epistêmica das faculdades da mente a que as crenças do senso comum são devidas. Minha hipótese afirma que a defesa dos princípios primeiros do senso comum é baseada em um argumento tripartite sobre as razões que temos para confiar na capacidade das faculdades cognitivas de produzir crenças verdadeiras. Em primeiro lugar, Reid mostra porque é impossível provar a fiabilidade das faculdades mentais e porque os filósofos, por esta razão, podem começar suas investigações aceitando a verdade das crenças destas faculdades. Este é o argumento da 'circularidade inevitável'. Em segundo lugar, Reid mostra que é inconsistente escolher uma das faculdades como única fonte fiável de crenças verdadeiras, como, por exemplo, a consciência. Isto é, segundo o filósofo, arbitrário. Este é o argumento da 'arbitrariedade filosófica'. Em terceiro lugar, se as faculdades da mente operam apropriadamente, isto é, quando a mente não é afetada por uma desordem ou doença, não há boas razões para colocar em questão sua fiabilidade e, portanto, questionar a verdade das crenças devidas a elas. Este é o argumento do 'funcionamento apropriado das faculdades'.

A hipótese que apresento é baseada principalmente sobre a interpretação da filosofia reidiana de autores como William Alston, Alvin Plantinga, Philip de Bary e John Greco. Estes autores me dão a base para pensar uma solução plausível para o problema de como Reid defende os princípios primeiros do senso comum do ataque cético. A originalidade deste artigo, ainda que ele se apoie sobre o trabalho destes autores, refere-se ao modo como estas interpretações (relativas ao primeiro e terceiro argumentos) são concatenadas com o segundo argumento que proponho.

Na primeira seção, apresento uma distinção entre as formas de ceticismo a que Reid se opõe, a saber, o 'ceticismo do sistema ideal' e o 'ceticismo sobre a fiabilidade epistêmica das faculdades da mente'. Afirmo que responder à primeira forma de ceticismo não é responder à segunda forma. Na segunda seção, apresento o problema ao qual esse artigo se refere, a questão de saber se Reid apresenta uma defesa filosófica dos princípios primeiros do senso comum ou se, ao contrário, ele se limitou a descrever as características psicológicas destas crenças - a 'imediaticidade', a 'irresistibilidade' e a 'universalidade'. Na terceira e última seção, apresento as três etapas que, a meu ver, constituem a defesa reidiana dos princípios primeiros, um argumento tripartite sobre as razões que temos para confiar na verdade das crenças do senso comum. 
Neste artigo, recorro, como textos básicos, à já citada Uma investigação sobre a mente humana a partir dos princípios do senso comum e aos Ensaios sobre os poderes intelectuais do homem $(1785)^{6}$, obras dedicadas essencialmente a questões epistemológicas. A outra grande obra de Reid, os Ensaios sobre os poderes ativos do homem $(1788)^{7}$, aparece apenas quando pode contribuir com algum exemplo que melhor esclareça os raciocínios e argumentos utilizados naquelas duas obras.

\section{As duas formas de ceticismo combatidas por Reid}

É possível afirmar que Reid combate ao menos duas formas de ceticismo em suas obras. Por um lado, o filósofo pretende responder ao ceticismo do 'sistema ideal'. Tal como Reid o entende, o sistema ideal tem uma relação muito próxima com o ceticismo. O sistema ideal é baseado sobre a hipótese de que as ideias são os únicos objetos imediatos das operações da mente ${ }^{8}$. Reid entende que as conclusões deste sistema são consequências necessárias da hipótese ideal:

Estes fatos inegáveis, em verdade, dão-nos motivo para compreender que o sistema do entendimento humano de Descartes, que peço permissão para chamar 'o sistema ideal', com algumas melhorias realizadas mais tarde pelos autores, e que agora é geralmente aceito, possui um defeito original: o ceticismo está incrustrado nele e com ele se desenvolve. Portanto, devemos examiná-lo até a sua fundação, examinando seus materiais, antes que possamos esperar erigir qualquer edifício sólido e útil do conhecimento neste assunto 9.

Ao ver de Reid, Hume teria sido o primeiro autor a levar esta hipótese ideal às suas últimas consequências ${ }^{10}$. As conclusões de Hume não seriam devidas a um erro em seus raciocínios. Pelo contrário, Hume apresentaria

\footnotetext{
${ }^{6}$ REID, T. Essays on the Intellectual Powers of Man. Edinburgh: Edinburgh University Press, 2002. ${ }^{7}$ REID, T. Essays on the Active Powers of Man. Edinburgh: Edinburgh University Press, 2010.

${ }^{8}$ Esta passagem resume a compreensão de Reid do sistema ideal: "os filósofos, com efeito, dizem-me que o objeto imediato da memória e, neste caso, da imaginação, não é uma sensação passada, mas uma ideia desta sensação, uma 'imagem', um 'fantasma', ou uma espécie do odor que cheirei. Dizem que esta ideia existe agora em minha mente, ou no sensório, que a mente contempla esta ideia presente, encontrando nela uma 'representação' do que é passado ou do que pode existir, chamando-a memória ou imaginação. Esta é a doutrina da filosofia ideal" (REID, 1997, p. 28).

${ }^{9}$ REID, 1997, p. 23.

${ }^{10}$ Reid diz: "o ceticismo moderno, quero dizer aquele de Hume, é construído sobre princípios que foram geralmente mantidos pelos Filósofos, embora eles não tenham visto que eles conduziriam ao ceticismo. O Sr. Hume, delineando com grande agudeza e engenhosidade as consequências dos princípios comumente recebidos, mostrou que eles derrubam todo o conhecimento e finalmente derrubam a si mesmos, e deixam a mente em perfeita suspenção" (REID, 2002, p. 461-462).
} 
conclusões corretamente deduzidas da hipótese ideal. Neste sentido, responder ao ceticismo do sistema ideal é atacar o fundamento deste sistema, a hipótese ideal ${ }^{11}$.

Neste artigo, foco sobre o segundo tipo de ceticismo que Reid pretende responder: o 'ceticismo sobre a fiabilidade epistêmica das faculdades da mente'. De modo conciso, o ceticismo sobre a fiabilidade das faculdades mentais é aquela forma de ceticismo que coloca em questão as crenças do senso comum - por exemplo, as crenças sobre as existências das operações da mente, dos eventos passados e dos objetos do mundo externo - em virtude de uma dúvida sobre as faculdades às quais elas são devidas. Nesta forma de ceticismo, o cético duvida, por exemplo, da verdade da crença sobre a existência do mundo externo a partir de uma dúvida sobre a faculdade de perceber o mundo. Não seria legítimo assumir como crenças verdadeiras, até que se prove a fiabilidade da percepção, as crenças sobre a existência dos objetos externos. Aqui, cito, como exemplo, a dúvida lançada por Descartes sobre a verdade das crenças dos sentidos nas Meditações sobre filosofia primeira $(1641)^{12}$. No fim da primeira meditação, com efeito, Descartes afirma:

Suporei, portanto, que não há um Deus ótimo, fonte soberana da verdade, mas algum gênio maligno e, ao mesmo tempo, sumamente poderoso e manhoso, que põe toda sua indústria em que me engane: pensarei que o céu, o ar, a terra, as cores, as figuras, os sons e todas as coisas externas nada mais são do que ludíbrios dos sonhos, ciladas que ele estende à minha credulidade. Pensarei que sou eu mesmo desprovido de mãos, de olhos, de carne, de sangue, de sentido algum, mas tenho a falsa opinião de que possuo tudo isso ${ }^{13}$.

Até que se prove que os sentidos são faculdades fiáveis, seria preciso duvidar das crenças devidas a eles. É a esta dúvida que me refiro quando penso que Reid procura responder ao ceticismo sobre a fiabilidade epistêmica das faculdades.

\footnotetext{
${ }^{11}$ De modo conciso, Reid tenta mostrar que os autores do sistema ideal nunca apresentaram uma evidência da existência de seu princípio, isto é, eles nunca provaram a existência das ideias. Por esta razão, a hipótese ideal seria apenas uma ficção da mente destes autores. Na Investigação, Reid afirma: "devemos examinar, mais tarde, esse sistema de ideias, esforçando-nos por mostrar: que nenhuma prova sólida jamais foi oferecida sobre a existência das ideias; que elas são meras ficções ou hipóteses, forjadas para solucionar os fenômenos do entendimento humano; que as ideias absolutamente não alcançam este fim; que esta hipótese de ideias ou imagens das coisas na mente, ou no sensório, é a causa daqueles muitos paradoxos tão chocantes ao senso comum e daquele ceticismo que envergonha nossa filosofia da mente, trazendo sobre ela o ridículo e o desprezo dos homens sensatos" (REID, 1997, p. 28). Nos Poderes intelectuais, Reid também discute mais detalhadamente porque a hipótese ideal deveria ser eliminada da filosofia (REID, 2002, p. 171-187).

${ }^{12}$ DESCARTES, R. Meditações sobre filosofia primeira. Campinas: Editora da Unicamp, 2004.

${ }^{13}$ DESCARTES, 2004, p. 31-32.
} 
O argumento tripartite que apresento na terceira seção deste artigo é uma resposta a este tipo de ceticismo. Afirmo a necessidade de se manter esta distinção entre duas formas de ceticismo tendo em vista evitar o equívoco de supor que a resposta à primeira forma de ceticismo (que surge no âmbito do sistema ideal) é uma condição suficiente para responder ao ceticismo e, consequentemente, garantir em alguma medida a legitimidade das crenças do senso comum como princípios primeiros verdadeiros.

Este parece ter sido o caso com a interpretação de Paul Vernier. Vernier argumenta, com efeito, que Reid justifica seus princípios primeiros observando que os filósofos céticos do sistema ideal não teriam boas razões para duvidar, uma vez que o princípio de seus sistemas é falso. Vernier argumenta que depois de afirmar que é impossível duvidar das crenças do senso comum - por elas serem naturais -, Reid chega a um segundo estágio:

A resposta de Reid, com efeito, é mover para um segundo estágio do argumento de que não há bases razoáveis para duvidar. Este estágio está direcionado ao nível epistêmico do discurso. É considerar se os argumentos céticos contra a garantia dos princípios do senso comum, a que somos impelidos a acreditar na vida cotidiana e que se sustentam tão bem neste cenário, são convincentes. De acordo com Reid, no entanto, as razões céticas para duvidar são todas insuficientes para apoiar sua posição $0^{14}$.

Responder ao ceticismo seria, neste sentido, questionar os princípios sobre os quais ele está fundado:

O ceticismo de Hume foi impressionante porque ele estava apoiado sobre princípios da filosofia que eram quase inquestionáveis desde os tempos de Descartes e porque ele considerou as deduções de Hume, a partir destes princípios, como sendo inquestionáveis. Por esta razão, ele começou por provar que as premissas do ceticismo de Hume, que ele encontrou na teoria das ideias, estavam erradas. Por esta via, ele acreditou que poderia minar o ceticismo humiano ${ }^{15}$.

Isto é, na visão de Vernier, a objeção de Reid à hipótese ideal é parte da justificação reidiana das crenças do senso comum como princípios do conhecimento.

A partir desta distinção entre duas formas de ceticismo, acredito ter tornado claro que colocar em questão a hipótese ideal não é suficiente para garantir a verdade dos princípios primeiros do senso comum. Atacar o princípio do sistema ideal não é uma resposta adequada à segunda forma

${ }^{14}$ VERNIER, P. "Thomas Reid on the Foundations of Knowledge and his Answer to Skepticism". In: Thomas Reid Critical Interpretations, Philadelphia: Philosophical Monographs, 1976, p. 20. ${ }^{15}$ VERNIER, 1976, p. 20. 
de ceticismo. É necessário responder ao cético que duvida da fiablidade das faculdades da mente. Como corretamente afirma T. J. Sutton:

O desafio cético volta-se para a noção de justificação. Sem uma justificação adequada, o argumento [cético] prossegue: não temos direito de afirmar o conhecimento ou mesmo ver nossas crenças como crenças racionais. Justificação é um conceito profundamente arraigado na tradição cética ${ }^{16}$.

\title{
2. Reid entre a psicologia e a epistemologia
}

\author{
Há intérpretes que questionam se Reid teria de fato ido além da descrição \\ psicológica das crenças do senso comum em sua defesa dos princípios \\ primeiros, deixando-os desprotegidos do ataque cético ${ }^{17}$. Com efeito, a
}

\footnotetext{
${ }^{16}$ SUTTON, T. J. “The Scottish Kant?" In: The Philosophy of Thomas Reid. Dordrecht / Boston / London: Kluwer Academic Publishers, 1989, p. 162.

${ }^{17}$ A título de ilustração, cito alguns intérpretes que apresentam a mesma pergunta de modo bastante eloquente. O filósofo Henry Sidgwick, por exemplo, em um artigo sobre a filosofia reidiana, observa a necessidade de uma distinção clara entre estes dois aspectos: "é necessário, em qualquer apreciação cuidadosa de seu trabalho, separar o processo de distinção e análise psicológicas, por meio dos quais as crenças fundamentais do senso comum são determinadas, dos argumentos pelos quais sua validade é justificada" (SIDGWICK, H. "The Philosophy of Common Sense". In: Mind, Volume IV, Número 14, 1895, p. 153). Vernier observa o mesmo ponto: "como pode ser reconhecido imediatamente, esta caracterização chama a atenção para uma resposta psicológica a uma proposição e não produz a sua garantia objetiva. Uma questão básica sobre a teoria dos fundamentos de Reid é saber se ele assume a autoevidência [a imeditaticidade e irresistibilidade] como a base para a garantia epistêmica das proposições fundamentais ou se ele considerou isto como sendo uma característica por meio da qual tal proposição pode ser reconhecida" (VERNIER, 1976, p. 15). William Alston também se interessa pela questão do valor atribuído por Reid ao argumento da imediaticidade e irresistibilidade das crenças. Ele a considera a partir do exemplo das crenças perceptivas, I: "o que podemos inferir sobre a natureza da realidade a partir de nossas tendências cognitivas inatas? Não poderíamos estar inatamente programados para produzir falsidades, ou, ao menos, produzir crenças que não são totalmente verdadeiras, embora possam ser úteis na prática? Estas considerações conferem um suporte sólido e racional para princípios como I" (ALSTON, W. "Thomas Reid on Epistemic Principles". In: History of Philosophy Quarterly, Volume II, Número 4, 1985, p. 443)? Sutton, por sua vez, coloca o problema nos seguintes termos: "se o apelo de Reid ao senso comum necessita ser fortalecido, precisamos mais do que umas poucas referências à intuição [à imediaticidade e à irresitibilidade] como explicação do porquê estamos justificados em nossa aceitação das crenças do senso comum. A questão permanece, mesmo assumindo que o senso comum possa ser um grau de razão particularmente apropriado para nos fornecer a crença nos princípios primeiros e que possa funcionar como uma forma de intuição, dando-nos conviç̧ão subjetiva sobre aquelas crenças. 'As crenças que o senso comum nos fornece são verdadeiras'? Se elas não o são, logo, ele falha em justificar os princípios primeiros como os fundamentos de nosso conhecimento" (SUTTON, 1989, p. 172-173). E também Philip de Bary o considera, a partir da questão de saber como Reid conecta a 'pretensão de inatismo' com a 'pretensão de verdade' dos princípios primeiros: "Reid claramente assume que as crenças que surgem sob os princípios primeiros, logo, "marcadas", são crenças verdadeiras (elas são 'princípios primeiros de verdades contingentes'). Contudo, as marcas (que em todo caso são sugestivas,
} 
ênfase dada pelo filósofo ao aspecto natural destas crenças pode fazer acreditar que, de acordo com ele, as crenças do senso comum seriam verdadeiras em virtude apenas de serem naturais. Reid teria apenas apontado as características psicológicas que marcam as crenças do senso comum, a convicção 'imediata e irresistível' e a 'universalidade'. Por um lado, estas crenças são imediatas porque não são fruto de raciocínio, por outro, são irresistíveis porque não está em poder dos seres humanos negar-lhes assentimento. Grande parte dos seres humanos assente de modo imediato e irresistível, por exemplo, à existência das operações e emoções da mente atestadas pela faculdade da consciência ${ }^{18}$. Ademais, uma crença ser aceita por grande parte dos seres humanos dotados de senso comum é outra das marcas de um princípio primeiro do senso comum ${ }^{19}$.

Algumas passagens de suas obras podem sugerir a interpretação de que Reid não vai além da descrição psicológica. Na Investigação, por exemplo, ele afirma: "para estes princípios nenhuma outra razão pode ser oferecida senão esta: pela constituição de nossa natureza, estamos sob uma necessidade de lhes dar assentimento ${ }^{20 \prime}$. Mesmo nos Poderes ativos, ao falar da faculdade moral, a consciência (conscience), Reid parece sugerir esta possibilidade:

Todo homem em seu senso acredita em seus olhos, ouvidos e outros sentidos. Ele acredita em sua consciência [consciousness] no tocante a seus próprios pensamentos e propósitos, sua memória, no tocante ao que é passado, seu entendimento, no tocante às relações abstratas das coisas, e em seu gosto,

não conclusivas) são marcas do que são estados puramente psicológicos. Reid pode estar tão correto quanto lhe apraz, descritivamente falando, sobre a gama de crenças que as pessoas instintivamente assumem como verdadeiras, assim como ele pode ter chegado, por abstração, a critérios seguros para identificar estas crenças inatas. Contudo, como o cético rapidamente apontará, tal descrição psicológica está além do objetivo epistemológico. Na ausência de um vínculo entre o que mais tarde deveremos chamar 'pretensão de inatismo' e 'pretensão de verdade' dos princípios primeiros, o desafio cético sobre sua garantia não terá sido refutado. Logo, a questão importante é: como Reid forja esse vínculo" (De BARY, P. Thomas Reid and Scepticism: his Reliabilist Response. London and New York: Routledge, 2002, p. 37)?

${ }^{18}$ Reid observa, por exemplo, ao discorrer sobre o princípio primeiro acerca da consciência: “a convicção irresistível da realidade daquelas operações não é um efeito do raciocínio: ela é imediata e intuitiva. Portanto, a existência daquelas paixões e operações de nossas mentes, das quais estamos conscientes, é um princípio primeiro que a natureza 'exige' que nele acreditemos à luz de sua autoridade" (REID, 2002, p. 470). De modo semelhante, ao falar sobre a crença perceptiva, o filósofo reconhece: "observei que esta convicção não é somente irresistível como também é imediata, isto é, não é por meio de uma corrente de raciocínios ou mediante argumentos que viemos a estar convencidos da existência do que é percebido. Não exigimos um argumento para a existência do objeto senão que o percebemos. A percepção comanda nossa crença por sua própria autoridade e não exige qualquer raciocínio para manter sua autoridade" (REID, 2002, p. 99).

${ }^{19}$ Reid afirma: “[...] concebo que o consentimento dos séculos e das nações, dos instruídos e dos não instruídos, deve ter uma grande autoridade no tocante aos princípios primeiros, onde cada homem é um juiz competente" (REID, 2002, p. 464).

${ }^{20}$ REID, 1997, p. 71. 
no tocante ao que é elegante e bonito. E ele tem a mesma 'necessidade de acreditar' nos ditames claros e não enviezados de sua consciência [conscience] no tocante ao que é honroso e ao que é vil ${ }^{21}$.

De acordo com esta linha de interpretação, tudo o que Reid tem a dizer em favor da verdade das crenças do senso comum é que elas são naturais e compartilhadas por grande parte dos seres humanos.

Esta é interpretação de Yves Michaud. O intérprete argumenta que Reid teria apelado de modo exagerado ao senso comum para questionar o sistema ideal e suas conclusões céticas. Michaud entende que Reid não justifica o senso comum e o senso comum, por si mesmo, não é capaz de responder à dúvida cética resultante da hipótese ideal. A própria dúvida cética poderia ser natural:

Como Hume claramente viu, sua força irresistível [das crenças naturais] é um remédio para as dúvidas céticas, contudo, ele se apressou em sublinhar que a disposição filosófica que traz à tona o ceticismo é tão natural quanto as crenças naturais o são. Nossas mentes seguem alternadas disposições que não refutam tampouco neutralizam uma à outra, mas simplesmente as alternam. $\mathrm{O}$ cético duvida e o homem comum acredita, mas nenhum refuta o outro. $\mathrm{O}$ caso pode ser que as primeiras e as últimas existem sucessivamente na mesma pessoa ${ }^{22}$.

De acordo com Michaud, afirmar que as crenças do senso comum são naturais não pode ser entendido como justificação, uma vez que isso seria apenas uma reafirmação delas: "o erro de Reid - mas um erro de qualquer filosofia do senso comum - é negligenciar o irresistível elemento cético que jaz no coração das próprias crenças naturais: elas são meramente naturais" ${ }^{23}$. A interpretação de Nicholas Wolterstorff também parece seguir

${ }^{21}$ REID, 2010, 180, aspas minhas.

${ }^{22}$ MICHAUD, Y. "Reid's Attack on the Theory of Ideas". In: The Philosophy of Thomas Reid. Dordrecht / Boston / London: Kluwer Academic Publishers, 1989, p. 16-17.

${ }^{23}$ MICHAUD, 1989, p. 31. Faço algumas observações sobre esta interpretação. Em primeiro lugar, Reid considera outra forma de ceticismo em suas obras, contrariamente ao que parece pensar o intérprete. Além do ceticismo do sistema ideal, Reid também tem em vista o ceticismo sobre a fiabilidade das faculdades da mente. Em segundo lugar, o apelo ao senso comum - a afirmação de que as crenças são naturais, imediatas e irresistíveis - não é o único argumento de Reid contra o sistema ideal. Com efeito, no capítulo 'Reflexões sobre a teoria comum das ideias' dos Poderes intelectuais (REID, 2002, pp. 171-187), ele apresenta cinco reflexões tendo em vista mostrar porque o sistema ideal falha como uma teoria explicativa das operações da mente. Apenas uma destas cinco reflexões diz respeito ao fato de que as conclusões do sistema ideal contradizem o senso comum. Em terceiro lugar, Michaud não explica em que sentido uma dúvida cética pode ser natural. É possível compreender como a reflexão filosófica é capaz de criar uma disposição à dúvida. Contudo, não é claro como uma dúvida cética sobre a existência dos objetos do mundo externo é semelhante (em relação à sua naturalidade) a uma crença do senso comum sobre a existência destes objetos. Essa dúvida pode ser uma determinação original da mente, uma disposição universalmente compartilhada pelos seres humanos? A dúvida cética parece não ter algumas das importan 
esta linha de leitura. No 'Prefácio' de sua obra Thomas Reid and the Story of Epistemology, o intérprete afirma que Reid não se interessaria pela justificação das crenças do senso comum:

As crenças surgem com uma variedade de méritos e deméritos relevantes à verdade. Elas são garantidas, confiáveis, formadas, autorizadas, justificadas, racionais, casos de conhecimento, aptas à inclusão na ciência, e assim por diante. A epistemologia contemporânea de tradição analítica preocupa-se, nos anos recentes, com a tentativa de oferecer uma análise de méritos como estes e critérios para sua aplicação. Uma pessoa treinada nesta tradição estará inclinada naturalmente a extrair de Reid uma teoria da garantia, uma teoria da autorização, uma teoria da justificação, ou o que quer que seja ${ }^{24}$.

O intérprete reconhece que, em algumas passagens, Reid parece se interessar por esta questão. Por isso, seria até mesmo possível desenvolver, a partir do que é apresentado por Reid, uma teoria reidiana referente aos méritos e deméritos das crenças no que diz respeito à verdade. Contudo, defende Wolterstorff, este não seria o principal projeto do filósofo: "ele claramente indica um interesse em desenvolver uma teoria geral da 'boa evidência', dos 'fundamentos exatos da crença'. Mas ele tem seu interesse frustrado ${ }^{25 \prime \prime}$. Ao ver de Wolterstorff, nada pode ser encontrado nas obras de Reid que não seja de caráter descritivo. Reid jamais se determinaria, em sua investigação, pelo propósito de justificar as crenças do senso comum, limitando-se, desse modo, à descrição dos mecanismos mentais do ser humano na percepção, memória e outras faculdades da mente ${ }^{26}$.

\section{A defesa tripartite dos principios primeiros do senso comum}

Tal como entendo a filosofia de Reid, o argumento psicológico sobre o imediaticidade e a irresistibilidade das crenças compartilhadas pela maior parte da humanidade é apenas o começo de sua defesa das crenças do senso comum. Reid tem mais a dizer sobre a verdade dos primeiros princípios do senso comum, apresentando três razões que, a meu ver, quando concatenadas, mostram a razão de os filósofos estarem legitimados em começar suas investigações pela aceitação da fiabilidade de todas as faculdades da mente e as crenças do senso comum.

\footnotetext{
tes marcas que nossas crenças naturais possuem. Em quarto lugar, contrariamente ao que Michaud sugere, e como argumentarei na seção seguinte, Reid vai além da mera descrição psicológica das crenças do senso comum.

${ }^{24}$ WOLTERSTORFF, N. Thomas Reid and the story of epistemology. New York, Cambridge

University Press, 2001, p. 02.

${ }^{25}$ WOLTERSTORFF, 2001, p. 03.

${ }^{26}$ WOLTERSTORFF, 2001, p. 197-198
} 


\section{I) A circularidade inevitável}

O primeiro argumento, que denomino 'argumento da circularidade inevitável', revela porque toda investigação filosófica poderia começar pela aceitação da fiabilidade de todas as faculdades da mente e, consequentemente, a verdade das crenças que a elas são devidas. Reid explica que o processo de tentar oferecer a prova da fiabilidade das faculdades cognitivas implica uma circularidade inevitável: é impossível provar este ponto sem apelar às próprias crenças devidas às faculdades cuja fiabilidade está em questão. O filósofo nota, no caso da discussão da fiabilidade da faculdade de raciocinar:

Se a honestidade de um homem é colocada em questão, seria ridículo remetermo-nos à palavra do próprio homem, seja ele honesta ou não. Há o mesmo absurdo na tentativa de provar, por qualquer tipo de raciocínio, provável ou demonstrativo, que nossa razão não é falaciosa, uma vez que o próprio ponto em questão é saber se podemos confiar no raciocínio ${ }^{27}$.

De acordo com o exemplo, existe uma circularidade inevitável em todo raciocínio pela veracidade da faculdade de racionar. O mesmo pode ser dito sobre a tentativa de se provar a fiabilidade de cada uma das faculdades da mente. Por exemplo: o processo de tentar provar a fiabilidade da percepção envolve uma circularidade na medida em seria preciso apelar às próprias crenças perceptivas - que estão em questão - para se provar que esta faculdade é fiável. Por isso, de acordo com Reid, toda tentativa de prova da fiabilidade das faculdades da mente é circular.

Tanto quanto sei, William Alston é o primeiro intérprete a chamar a atenção para a importância desse argumento para a teoria reidiana dos princípios primeiros do senso comum. A seu ver, este argumento pode mostrar em que sentido a exigência cética da prova da fiabilidade das faculdades é impossível de ser satisfeita:

Se o cético se queixa que nenhuma razão adequada pode ser oferecida à fiabilidade da percepção dos sentidos, podemos responder que a circularidade apontada mostra que o mesmo pode ser dito sobre qualquer faculdade que ele favoreça, qualquer faculdade que ele exclua de seu escrutínio crítico $^{28}$.

Não afirmo, assim como Alston também não o faz, que o argumento da circularidade prova a verdade das crenças do senso comum. Este argumento não é uma prova da verdade das crenças do senso comum. Contudo, o argumento mostra que temos boas razões para supor a verdade destas crenças diante da impossibilidade se provar a fiabilidade das faculdades mentais. Com efeito, Reid mostra que o cético encontra-se diante de um

\footnotetext{
${ }^{27}$ REID, 2002, p. 480.

${ }^{28}$ ALSTON, 1985, p. 446.
} 
dilema: negar a fiabilidade de todas as faculdades mentais - assumindo uma forma radical de ceticismo - ou aceitar igualmente a fiabilidade de todas elas, pois nenhuma estaria mais assegurada que outra:

Portanto, o que Reid nos ensina sobre os fundamentos da epistemologia é que não existe racionalmente nenhuma alternativa atrativa senão aceitar o testemunho de nossas faculdades cognitivas básicas como (prima facie) corretas e que apenas se fizermos isso teremos alguma chance de adquirir qualquer conhecimento ${ }^{29}$.

Diferentemente de Alston, no entanto, acredito que a resposta de Reid não se resume a este argumento da circularidade. $\mathrm{O}$ filósofo tem mais a dizer em favor da verdade dos princípios primeiros.

\section{II) A arbitrariedade filosófica}

Chamo o segundo passo da defesa reidiana de 'argumento da arbitrariedade filosófica'. Em suma, este argumento estabelece que, no contexto em que não se pode provar a fiabilidade de nenhuma das faculdades sem incorrer em circularidade, não se pode, do mesmo modo, escolher uma única faculdade como fonte fiável de crenças verdadeiras, preterindo todas as demais. Toda escolha seria, em último caso, arbitrária. Reid discute este argumento, tanto na Investigação quanto nos Poderes intelectuais, a partir da observação do privilégio que a faculdade da consciência possui entre os filósofos modernos.

Na Investigação, Reid considera a arbitrariedade dos filósofos na escolha dos princípios primeiros, chamando atenção para o caráter imediato e irresistível que caracteriza igualmente as crenças que são devidas às operações das faculdades mentais. As crenças da consciência, memória, percepção e consciência moral, por exemplo, são todas imediatas e irresistíveis. Não há porque privilegiar uma fonte de crenças em detrimento de outras. Reid considera notável que o mais radical dos céticos do sistema ideal, Hume, tenha se rendido ante à força de um dos princípios primeiros em particular:

O autor do 'Tratado da natureza humana' parece-me ser antes um cético parcial. Ele não levou o seu princípio tão longe quanto ele poderia levá-lo. Depois de ter combatido, com intrepidez e sucesso sem precedentes, os preconceitos vulgares, quando ele tinha apenas um golpe a desferir, a sua coragem falhou, de modo que ele depôs justamente suas armas, tornando-se cativo do mais comum de todos os preconceitos vulgares, quero dizer, a crença na existência de suas próprias impressões e ideias ${ }^{30}$.

Para Reid, Hume foi incapaz de negar a verdade das crenças da consciência. Hume não pôde, não obstante toda a força de seus argumentos

${ }^{29}$ ALSTON, 1985, p. 449.

${ }^{30}$ REID, 1997, p. 71. 
filosóficos deduzidos a partir da hipótese ideal, duvidar da existência das operações de sua mente. A crença imediata e irresistível na existência das operações, paixões e emoções apontadas pela consciência não permitiu que ele adotasse a forma mais radical de ceticismo. Com essa concessão da parte de Hume, Reid acredita ter encontrado um forte argumento em favor de sua defesa: se se aceita um dos princípios primeiros, isto é, se se assume como certo a existência das operações da mente testemunhadas pela consciência, por que razão não assumir, do mesmo modo, todos os outros princípios sugeridos pela mente humana?

O que há nas impressões e ideias de tão formidável que esta filosofia que tudo conquista, depois de triunfar sobre todas as outras existências, deve prestar-lhes homenagem? Além disso, essa concessão é perigosa, visto que a crença é de tal natureza que, se você deixar qualquer raiz, ela se espalhará $[\ldots]^{31}$.

A crença devida à consciência em nada se distingue, no tocante à sua imediaticidade e irresistibilidade, às crenças devidas às faculdades da memória e percepção. Se se aceita as crenças da consciência, em que medida é possível negar outras tantas fontes de crenças? O caráter imediato e irresistível da crença na existência das impressões e ideias é o mesmo da crença na existência dos eventos passados (crença da memória) e da crença na existência dos objetos do mundo exterior (crença perceptiva). É este processo de escolher uma faculdade em detrimento de outras que é chamado arbitrário.

Nos Poderes intelectuais, ao considerar a história da filosofia, Reid nota que as crenças da consciência jamais foram colocadas em questão. Por exemplo, ao considerar a primeira descoberta da filosofia cartesiana, expressa pelo célebre entimema, 'penso, logo existo', Reid observa que Descartes apoiou-se fundamentalmente sobre esta crença: "se fosse perguntado como Descartes veio a estar certo desta proposição antecedente [isto é, penso], é evidente que para isso ele confiou no testemunho da consciência. Ele estava consciente que ele pensava, não precisando de nenhum outro argumento $^{32 \prime \prime}$. Ou seja, para que Descartes fosse capaz de saber que pensa e que, portanto, ele existe, ele teve de assumir como certo, primeiramente, que sua consciência é uma fonte fiável sobre a existência de suas operações mentais. Descartes "adota em seu famoso entimema que aquelas dúvidas, pensamentos e raciocínios de que ele estava consciente certamente existiam, de modo que sua consciência colocava a existência daqueles além de qualquer dúvida ${ }^{33 "}$. Descartes não provou que a consciência produz crenças verdadeiras. O que legitima, deste modo, sua aceitação desta

\footnotetext{
${ }^{31}$ REID, 1997, p. 71.

${ }^{32}$ REID, 2002, p. 51.

${ }^{33}$ REID, 2002, p. 515.
} 
crença? "A esta objeção, não conheço nenhuma outra resposta que possa ser apresentada senão que descobrimos ser impossível duvidar das coisas de que estamos conscientes. A 'constituição de nossa natureza' obriga esta crença sobre nós irresistivelmente ${ }^{34 "}$. Em outras palavras, são as próprias características da convicção que acompanha a consciência, a irresistibilidade e imediaticidade das crenças por ela produzidas, que autorizam Descartes a confiar completamente no testemunho desta faculdade, a acreditar na existência das operações da mente. Aceita-se a consciência como fonte fiável de conhecimento por sua imediaticidade e irresistibilidade. Por que não aceitar todas as outras faculdades a que crenças imediatas e irresistíveis são devidas? Mais uma vez: é arbitrário, da parte dos filósofos, aceitar a consciência e não as outras faculdades.

Se é impossível provar a fiabilidade das faculdades da mente, por qual razão um filósofo estaria legitimado a escolher a consciência, como fonte fiável de crenças verdadeiras, se todas as crenças do senso comum são igualmente imediatas e irresistíveis? Poder-se-ia argumentar, contra este argumento de Reid, que se Descartes e Hume escolheram a consciência como fonte fiável de crenças verdadeiras e colocaram em questão a percepção, eles o fizeram a partir de argumentos. A escolha, portanto, não seria arbitrária, seria racional: existem argumentos que motivariam a escolha de uma faculdade em particular e a dúvida sobre as demais. A resposta reidiana a este questionamento é clara: no contexto em que é impossível provar a fiabilidade das faculdades da mente, a razão não estaria mais disponível aos filósofos que as demais faculdades. A razão não possui nenhum estatuto privilegiado como fonte de crenças verdadeiras. O processo de apresentar argumentos envolveria uma inconsistência, pois escolher-se-ia - arbitrariamente - a faculdade da razão para julgar outras faculdades. Qual o privilégio, argumenta Reid, da razão em detrimento de outras faculdades? Por que ela seria uma fonte mais fiável para avaliar outras faculdades? Argumentar em favor de uma faculdade em detrimento de outras é tão arbitrário quanto escolher a faculdade da consciência como fonte fiável de crenças verdadeiras:

Então, as faculdades da consciência, memória, sentidos externos e razão, são todas igualmente dons da natureza. Nenhuma razão pode ser apontada para receber o testemunho de uma delas que não seja de igual força com relação às outras. Os maiores céticos admitiram o testemunho da consciência e admitiram que o que ela testemunha deveria ser mantido como um princípio primeiro. Se portanto eles rejeitam o testemunho imediato dos sentidos ou da memória, eles são culpados de inconsistência ${ }^{35}$.

Este procedimento arbitrário, seja na escolha da consciência, seja na escolha da razão - donde se originariam argumentos em favor ou contra a

${ }^{34}$ REID, 2002, p. 515, aspas minhas.

${ }^{35}$ REID, 2002, p. 463. 
fiabilidade de uma faculdade -, não é legítimo: "portanto, as faculdades da consciência, da memória, dos sentidos externos e da razão são todas igualmente dons da natureza. Não se pode atribuir nenhuma razão para receber o testemunho de uma delas que não seja de igual força em relação às outras ${ }^{36 \prime \prime}$.

\section{III) O funcionamento apropriado das faculdades mentais}

Por fim, apresento o argumento do funcionamento apropriado das faculdades da mente. O filósofo Alvin Plantinga desenvolve uma 'teoria da garantia ou aval epistêmico' a partir, grosso modo, da ideia de que o funcionamento apropriado das faculdades mentais é fundamental para garantir o conhecimento humano. Plantinga, após uma breve consideração de algumas das principais teorias contemporâneas da justificação (em específico, as teorias de Roderick Chisholm, Keith Lehrer, Fred Dretske e Alvin Goldman), reconhece o ponto central do que virá a ser a ideia básica de sua teoria:

Há um tipo de tema recorrente nas discussões acima. Vimos repetidas vezes que diversas análises propostas da justificação afundam quando refletimos sobre a variedade de modos em que nossas faculdades noéticas podem falhar em funcionar apropriadamente. [...] Sugiro que, em cada caso, a razão é o 'malfuncionamento cognitivo', uma falha das faculdades cognitivas relevantes para funcionar apropriadamente ${ }^{37}$.

À luz desta consideração, Plantiga estabelece:

Portanto, sugiro que uma condição necessária para o estatuto epistêmico positivo é que o equipamento cognitivo, o aparato de formação e manutenção de crenças, esteja livre de tal malfuncionamento cognitivo. Uma crença possui estatuto epistêmico positivo, a meu ver, somente se o meu aparato cognitivo estiver funcionando apropriadamente, operando da maneira que deveria operar ao produzir e manter $\operatorname{crenças~}^{38}$.

É importante chamar a atenção para uma das inspirações de Platinga para a formulação da teoria apresentada acima. Em uma passagem em que ele reconhece os autores aos quais deve sua tese, ele confessa, com efeito: "outro débito intelectual, a posição que desenvolverei é, de maneira geral, reidiana: o esboço global da epistemologia de Thomas

\footnotetext{
${ }^{36}$ REID, 2002, p. 463.

${ }^{37}$ PLANTINGA, A. "Positive Epistemic Status and Proper Function". In: Philosophical Perspectives, Volume II, 1988, p. 32.

${ }^{38}$ PLANTINGA, 1988, p. 32.
} 
Reid me parece largamente correto ${ }^{39 \prime}$. A discussão de Plantinga é empreendida, é claro, em um contexto bastante distinto daquele contexto no qual a filosofia reidiana está inserida. Foco, no entanto, na ideia básica de Plantinga, reconhecida por ele como sendo inspirada por Reid: as várias fontes de crenças são igualmente fiáveis enquanto funcionam de modo apropriado.

Diversas passagens dos Poderes intelectuais sugerem que Reid está de fato interessado pela questão do modo como funcionam as faculdades da mente. No que diz respeito à defesa das crenças do senso comum, Reid argumenta que não existem motivos para se questionar a fiabilidade das faculdades mentais quando elas estão em boas e saudáveis condições, visto que os erros muitas vezes podem ser explicados mais por desordens e enfermidades que afetam a mente do que por uma inclinação geral da mente ao engano. Por exemplo, ao discutir a admissão dos seres humanos das crenças produzidas de modo imediato e irresistível na mente, Reid afirma:

Tudo o que tenho a dizer sobre isso é que nossas mentes estão sujeitas em nosso estado presente, assim como os corpos, a desordens estranhas. Como não podemos julgar a constituição natural do corpo a partir das desordens e doenças às quais ele está sujeito por acidente, do mesmo modo, não devemos julgar os poderes naturais da mente a partir das desordens, mas a partir de seu estado saudável ${ }^{40}$.

Em outra passagem, Reid nega que os erros decorrentes das faculdades mentais afetadas por alguma desordem sejam suficientes para se considerar estas faculdades como sendo falaciosas: "imaginação, memória e os poderes de julgar e raciocinar estão todos sujeitos a ferimentos, ou mesmo à destruição, por desordens do corpo, assim como nossos poderes de percepção, contudo, nesta explicação, não os chamo de falaciosos ${ }^{41 "}$. O filósofo é ainda mais explícito sobre o fato de que os erros são mais decorrentes de certas desordens e enfermidades que afligem a mente do que de uma inclinação geral da mente ao engano:

Nossos poderes intelectuais foram adaptados sabiamente pelo Autor de nossa natureza para a descoberta da verdade, sendo também adequados para o nosso estado presente. $\mathrm{O}$ erro não é mais o seu produto natural que a doença o é da estrutura natural do corpo. No entanto, como estamos sujeitos a diversas doenças do corpo de causas acidentais, externas e internas, também estamos sujeitos a julgamentos errados a partir de causas semelhantes ${ }^{42}$.

\footnotetext{
${ }^{39}$ PLANTINGA, A. Warrant and proper function. New York / Oxford: Oxford University Press, 1993, p. X.

${ }^{40}$ REID, 2002, p. 98.

${ }^{41}$ REID, 2002, p. 243-244.

${ }^{42}$ REID, 2002, p. 527.
} 
Além de Plantinga, Philip de Bary ${ }^{43}$ e John Greco $^{44}$ também defendem a interpretação de que o funcionamento apropriado das faculdades da mente é o que garante a verdade das crenças do senso comum na filosofia de Reid. Diferentemente destes intérpretes, no entanto, entendo que este argumento ganha força principalmente quando concatenado com os argumentos da circularidade e da arbitrariedade. Com efeito, é possível que se objete que o argumento do funcionamento adequado também incorreria em circularidade: como seria possível avaliar que uma faculdade opera de modo apropriado sem apelar às crenças da própria faculdade cuja fiabilidade está sendo questionada? Como avaliar o funcionamento, por exemplo, da percepção, sem ter em vista as crenças devidas a esta faculdade?

A esta possível objeção, argumento que o processo de avaliar o funcionamento das operações mentais pode ser realizado conjuntamente por todas as faculdades, desde que, primeiramente, o filósofo tenha aceitado igualmente a fiabilidade de todas elas. Diante do argumento da circularidade e da arbitrariedade, o filósofo vê-se diante da necessidade - para não assumir uma forma radical de ceticismo - de assumir a consciência, a memória, a percepção e as outras faculdades como fontes fiáveis de conhecimento. Dispondo de todas as faculdades, a avaliação de uma faculdade em particular pode ser realizada por outras. A percepção pode ser avaliada pela consciência, memória, razão; a memória, pela consciência, pela razão. A partir da premissa que todas as faculdades são fiáveis, é possível se valer de todas elas para avaliar o funcionamento das operações mentais.

Certamente, o argumento do funcionamento apropriado das faculdades não prova a verdade das crenças do senso comum, como o primeiro e o segundo argumentos também não o provam. No entanto, ele se torna eficaz em face, por um lado, da impossibilidade de apresentar a prova da confiabilidade das faculdades mentais e, por outro lado, da ilegitimidade da escolha de apenas uma faculdade como fonte fiável de conhecimento. Diante destas dificuldades, Reid sugere: não temos boas razões para duvi-

\footnotetext{
${ }^{43}$ Para De Bary, apenas a identificação de uma causa geral de erro poderia colocar em questão a verdade das crenças do senso comum: elas "estão prima facie justificadas, ou são 'inocentes até que seja provado que são culpadas'. Se quisermos, é como um fiabilismo com um 'epiciclo': as crenças verdadeiras do senso comum são justificadas, equivalendo a conhecimento, apenas na medida em que o crente não tem uma boa razão para delas duvidar" (DE BARY, 2002, p. 86). Uma vez que nossas faculdades operam apropriadamente, o cético não teria boas razões para delas duvidar.

${ }^{44}$ Greco sustenta que Reid mantém um tipo de 'fiabilismo do funcionamento apropriado das faculdades da mente': "em geral, o estatuto epistêmico positivo deriva do funcionamento apropriado de nossas faculdades cognitivas naturais e não falaciosas. As faculdades que compõem o senso comum (por exemplo, a percepção, a memória e a consciência) são faculdades deste tipo. Como tais, elas têm a mesma autoridade da razão, e com todas as outras faculdades cognitivas não falaciosas. Uma vez que elas não são faculdades inferenciais (não são raciocínio), elas são fontes não-inferenciais de conhecimento" (GRECO, J. "Common Sense in Thomas Reid". In: Canadian Journal of Philosophy, Volume XLI, Número 1, p. 142-155, 2014, p. 149).
} 
dar da fiabilidade de nossas faculdades se elas operam apropriadamente, se nossas mentes não foram afetadas por algum distúrbio ou doença. Por que o cético suporia que as faculdades mentais, quando funcionam apropriadamente, não são fiáveis? "O entendimento, em seu estado natural e melhor, presta homenagem apenas à verdade ${ }^{45 "}$.

\section{IV) A resposta ao ceticismo a partir dos três argumentos}

Apresentados os três argumentos, recapitulo agora o modo como os concateno para construir uma defesa consistente das crenças do senso comum. O passo inicial de Reid é mostrar que todos os raciocínios para provar a fiabilidade das faculdades - a prova exigida pelo cético - implicam uma circularidade inevitável. Os filósofos não conseguiriam provar este ponto sem incorrer em inconsistência. O segundo passo é mostrar que escolher uma única faculdade como fonte de crenças fiáveis é tão inconsistente quanto tentar oferecer uma prova da fiabilidade das faculdades. Ao fazer isso, os filósofos poderiam ser acusados de arbitrariedade. $\mathrm{O}$ último passo completa o propósito de defender a fiabilidade das faculdades mentais e a verdade das crenças por elas produzidas: se não somos capazes de provar sua fiabilidade, nem podemos escolher uma delas como uma fonte fiável de crenças verdadeiras, é necessário abraçar uma posição cética sobre a verdade das crenças do senso comum? A resposta de Reid é negativa: não temos muitos motivos para delas duvidar se as faculdades operarem apropriadamente, se não identificarmos uma causa geral de erros em suas operações. Por que supor que, mesmo quando funcionam em boas e saudáveis condições, as faculdades não são fiáveis?

É possível questionar se este argumento de Reid não seria, na verdade, cético, uma vez que começa por reconhecer a impossibilidade de se provar a fiabilidade das faculdades mentais. Reid chega a reconhecer essa possibilidade em uma passagem:

Acredito que devemos presumir que o homem e provavelmente todo ser criado é falível, sendo que todo ser falível não pode possuir uma compreensão perfeita e segura da verdade tal como a possui um ser infalível. [...]. Se isso pode ser chamado um 'grau de ceticismo', não posso evitar de aprová-lo, sendo persuadido de que o homem que faz o melhor uso possível das faculdades que Deus lhe deu, sem pensar ser mais perfeito do que ele realmente o é, pode manter todas as crenças necessárias na conduta da vida assim como para a aceitação de seu Criador ${ }^{46}$.

Sobre este caráter cético do argumento acerca da impossibilidade de se provar a fiabilidade das faculdades, Garrett Allen nota:

${ }^{45}$ REID, 2002, p. 527-528.

${ }^{46}$ REID, 2002, p. 563-564. 
Sua [de Reid] adição ao modelo cético tornou o sistema cético completo. O cético admitiu que o uso de nenhuma faculdade cognitiva está livre de circularidade epistêmica, anulando assim todas as crenças. A posição reidiana parece melhor, pois envolve crenças, e portanto permite a possibilidade de conhecimento do mundo ${ }^{47}$.

De fato, o argumento de Reid não elimina a possibilidade da dúvida sobre as crenças do senso comum. O cético está legitimado em manter sua dúvida. É impossível provar que não estamos sendo enganados nos usos das faculdades mentais e, por isso, os argumentos de Reid não são suficientes para responder completamente ao ceticismo. Contudo, e talvez este seja o grande mérito do argumento reidiano, ele mostra que, ao cético, restam apenas duas possibilidades. Em primeiro lugar, o cético pode optar por negar a fiabilidade de todas as faculdades e, consequentemente, assumir o tipo mais radical de ceticismo. Contudo, ao negar igualmente todas as faculdades como fontes fiáveis, o cético acaba negando a possibilidade de qualquer tipo de conhecimento. Existiria algum princípio a partir do qual a filosofia se devenvolveria, uma vez que todas as faculdades da mente foram questionadas? Em segundo lugar, o cético pode optar por aceitar a fiabildade de todas as faculdades mentais. Reid mostra que temos boas razões para supor a verdade das crenças do senso comum. Em face da possibilidade de se adotar um ceticismo radical, Reid aponta algumas razões para se aceitar o senso comum como uma fonte confiável de crenças e, portanto, como fundamento do conhecimento humano.

\section{Conclusão}

Ao longo do artigo, procurei apresentar os argumentos que, a meu ver, compõem a defesa de Reid dos princípios primeiros do senso comum do ataque cético. Antes de me deter sobre estes argumentos, no entanto, expliquei porque seria preciso, para uma compreensão adequada da defesa reidiana, distinguir as duas formas de ceticismo contra as quais o filósofo se opõe. Responder ao ceticismo do sistema ideal não é responder ao ceticismo sobre a fiabilidade epistêmica das faculdades às quais são devidas as crenças do senso comum. Para defender a verdade dos princípios primeiros do senso comum, é preciso esclarecer de que modo as faculdades mentais - consciência, memória, percepção, e consciência moral, por exemplo - são fontes fiáveis de crenças verdadeiras. E, para isso, Reid não se limita a afirmar, como quiseram alguns intérpretes, que as crenças do senso comum são verdadeiras porque são naturais. O filósofo não confundiu psicologia e epistemologia, tampouco abandonou o projeto de discutir a verdade das crenças do senso comum. Reid mostra

${ }^{47}$ ALLEN, G. “Understanding Thomas Reid”. In: Stance, Volume V, 2012, p. 62. 
as razões que temos para começar a investigação filosófica assumindo as crenças do senso comum como crenças verdadeiras.

Se estou correto em minha interpretação, é possível encontrar em Reid um argumento composto de três etapas. Em primeiro lugar, o filósofo mostra em que medida seria impossível provar a fiabilidade das faculdades da mente sem incorrer em circularidade: não é possível julgar, por exemplo, a fiabilidade da percepção, sem recorrer a crenças perceptivas que são devidas à própria faculdade cuja fiabilidade está em questão. Esta circularidade inevitável está presente em toda tentativa de prova da fiabilidade das faculdades. Reid mostra, em segundo lugar, porque é arbitrário, da parte dos filósofos, escolher uma única faculdade como fonte fiável de crenças verdadeiras. Descartes e Hume, por exemplo, teriam incorrido neste erro ao assumir apenas a consciência como fonte de crenças verdadeiras. Ao ver de Reid, isso ocorreu porque eles não teriam sido capazes de duvidar das crenças imediatas e irresistíveis da consciência. Contudo, o filósofo nota, esta imediaticidade e irresistibilidade caracterizam todas as demais crenças do senso comum - por exemplo, as crenças da memória, da percepção e da consciência moral. No contexto em que é impossível provar a fiabilidade das faculdades mentais, é arbitrário escolher apenas uma faculdade e duvidar de todas as outras a que são devidas crenças igualmente imediatas e irresistíveis. Em terceiro lugar, Reid mostra que não é preciso assumir uma posição cética diante da impossibilidade de provar a verdade das crenças do senso comum. Seu argumento é: uma vez que as faculdades estão funcionando apropriadamente, isto é, quando a mente humana não é afetada por qualquer desordem ou enfermidade, não há boas razões para colocar em questão a fiabilidade dessas faculdades e, portanto, questionar a verdade de suas crenças. Temos boas razões para confiar nas faculdades da mente ao invés de negar a fiabilidade de todas elas. A meu ver, portanto, estas três etapas constituem a resposta de Reid ao ceticismo sobre a fiabilidade epistêmica das faculdades da mente.

\section{Referências}

ALLEN, G. "Understanding Thomas Reid". In: Stance, Volume V, 2012, pp. 55-62. ALSTON, W. "Thomas Reid on Epistemic Principles". In: History of Philosophy Quarterly, Volume II, Número 4, 1985, p. 435-453.

De BARY, P. Thomas Reid and Scepticism: His Reliabilist Response. London and New York: Routledge, 2002.

CHARLES, S. \& SMITH, P. Scepticism in the Eighteenth Century: Enlightenment, Lumières, Aufklärung. New York Springer, 2013.

DESCARTES, R. Meditações sobre filosofia primeira. Edição bilíngüe. Tradução de Fausto Castilho. Campinas: Editora da Unicamp, 2004. 
ETCHEGARAY, C. “Can We Know Whether Scepticism is Right or Wrong? Reid's Criticism and Hume's answer". In: Scepticism in the Eighteenth Century. Editado por Sébastien Charles e Plínio Smith. New York Springer, 2013, p. 139-154.

FRASER, A. C. Thomas Reid. New York: Charles Scribner's Sons, 1898.

FREITAS, V. "A noção de senso comum em Thomas Reid". In: Discurso, 2020. No prelo.

GRECO, J. "Common Sense in Thomas Reid". In: Canadian Journal of Philosophy, Volume XLI, Número 1, 2014, p. 142-155.

JAFFRO, L. “Les Recours Philosophique au Sens Commun dans les Lumières Britanniques". In: Le sens Commun. Editado por J. P. Sylvestre e P. Guenancia. Dijon: Editions Universitaires de Dijon, 2006.

MICHAUD, Y. "Reid's Attack on the Theory of Ideas". In: The Philosophy of Thomas Reid. Editado por Melvin Dalgarno e Erick Matthews. Dordrecht / Boston / London: Kluwer Academic Publishers, 1989.

PLANTINGA, A. “Positive Epistemic Status and Proper Function”. In: Philosophical Perspectives, Volume II, 1988, p. 01-50.

versity Press, 1993.

. Warrant and Proper Function. New York / Oxford: Oxford Uni-

REID, T. Essays on the Active Powers of Man. Editado por Knud Haakonssen e James A. Harris. Edinburgh: Edinburgh University Press, 2010.

. Essays on the Intellectual Powers of Man". Editado por Derek Brookes. Edinburgh: Edinburgh University Press, 2002.

. Inquiry into the Human Mind on the Principles of Common Sense. Editado por Derek Brookes. Edinburgh: Edinburgh University Press, 1997.

SIDGWICK, H. “The Philosophy of Common Sense". In: Mind, Volume IV, Número 14, 1895, p. 145-158.

SUTTON, T. J. "The Scottish Kant?" In: The Philosophy of Thomas Reid. Editado por Melvin Dalgarno e Erick Matthews. Dordrecht / Boston / London: Kluwer Academic Publishers, 1989.

VERNIER, P. "Thomas Reid on the Foundations of Knowledge and His Answer to Skepticism". In: Thomas Reid Critical Interpretations. Editado por S. Barker e T. Beauchamp. Philadelphia: Philosophical Monographs, 1976.

WOLTERSTORFF, N. Thomas Reid and the story of epistemology. New York, Cambridge University Press, 2001.

Endereço do Autor:

Rua Flor de Índio, 100, Bl T, Apto. 204

Bairro Indaiá

31270215 Belo Horizonte - MG

ffvinicius@yahoo.com.br 